\title{
BOVINE INFECTIOUS ABORTION, EPIZOOTIC AMONG GUINEA-PIGS.*
}

FRANK M. SURFACE.

(From the Biological Laboratory of the Kentucky Agricultural Experiment Station, Lexington, $K y$.)

The statement has frequently been made that, while the bacillus of bovine contagious abortion (Bacillus abortus, Bang) will cause abortion in other domestic or laboratory animals when experimentally inoculated, it is not known to be epizootic among any animals except cattle. Abortion of an epizootic nature occurs not infrequently with horses, sheep, and swine. In no instance, however, has such a case been connected with the organism found in cattle. There is a considerable body of evidence to show that the natural infection of animals other than cattle with this organism must be exceedingly rare. However, the ease with which other species of animals may be artificially infected leaves it by no means certain that under the proper conditions natural infection might not occur. In this connection, the following observations are of interest.

In I 908 the Department of Animal Husbandry of this station began some work with infectious abortion. From that time until the end of I9I I number of guinea-pigs were inoculated from time to time with material from aborting cows. During the year I9I I a number of these animals were inoculated with pure cultures of the bacillus abortus. During this period the space for keeping inoculated animals was very limited. A room in the station piggery had been fitted up as a growing room for such small animals. During a large portion of the year there was no place suitable for inoculated pigs except in this room. The inoculated pigs were kept in wire cages of the Vaughan type. These cages were on legs about six inches high, and were placed in the growing pens so that the healthy pigs could run under the cages. No inoculated pigs were ever returned to the general herd and none of the healthy animals could come in contact with the infected pigs except through the one-eighth inch wire screen on the sides of the cages. However, such an arrangement allowed infected litter and urine to reach the

* Received for publication September 10, Igr2. 
outside of the cages, and thus to come in contact with the healthy animals.

In January of the present year I undertook some extensive experiments on the diagnosis of bovine infectious abortion, ${ }^{\mathrm{I}}$ using the agglutination and complement fixation reaction. In this latter test guinea-pig's blood was used for the complement. In the beginning some very puzzling results were obtained in which control tubes containing only complement and antigen showed complete fixation of the complement. It was first believed that there was some trouble with the antigen, and various modifications of this were tried without avail. It was then noticed that this result was obtained only with the serum of certain guinea-pigs. The serum of such pigs was then tested for its ability to agglutinate the abortion bacilli. It was found that the serum of such pigs agglutinated the abortion bacilli very strongly, even in dilutions of I to I,500 or higher. The serum of those guinea-pigs which did. not fix the complement likewise did not agglutinate the abortion bacilli. It is thus practically certain that these guinea-pigs had been infected with the abortion bacilli and that for this reason their blood contained abortion amboceptors.

Records have been kept of 43 guinea-pigs killed for complement from this general herd. Of these the blood of 29 showed the presence of abortion amboceptors, while I4, mostly young pigs, gave no evidence of infection. The sera of $\mathrm{r} 2$ of the 29 guinea-pigs which showed fixation of the complement were also tested for agglutination. In every case the serum gave a strong agglutination.

To all appearances the herd of guinea-pigs is perfectly healthy and vigorous. We have noticed an occasional pig showing paralysis of the hind quarters but these occur so rarely that no importance is attached to it. However, it is certain that the herd is not multiplying as rapidly as formerly, although no definite data regarding this can be given. If abortions occur in any number, the products are eaten so quickly that they are rarely seen. Under the conditions in which the animals are kept this could very wcll happen. When pregnant females have been confined we have often observed abortions.

×Ky. Agric. Exp. Sta., Annual Report, I9 2. Bull. No. ז66, pp. $30 \mathrm{r}, 366$. 
Smith and Fabyan ${ }^{\mathrm{x}}$ have recently pointed out that guinea-pigs inoculated with the Bang bacillus present certain characteristic lesions. One of the more marked pathological changes is the enlargement of the spleen which occurred in 98 per cent of the cases examined by them.

It is thus of some interest to go through our autopsy records and note the condition of this organ in connection with these blood tests. It is a rule of the laboratory to make autopsy records, including the weights of the principal organs, of every animal killed. Unfortunately, on account of the lack of proper facilities, complete records were not kept on all the guinea-pigs killed in the earlier part of this work. Since the first of March, however, the records are fairly complete. A portion of these records with respect to spleen weight are shown in the following table:

\begin{tabular}{|c|c|c|c|c|c|}
\hline \multicolumn{3}{|c|}{$\begin{array}{l}\text { GuINEA-Pigs SHOWING a BLOOD Reaction } \\
\text { WITH ABortion ANTIGEN }\end{array}$} & \multicolumn{3}{|c|}{ Guinea-Pigs Showing no Blood Reaction } \\
\hline $\begin{array}{l}\text { Body Weight, } \\
\text { Grams }\end{array}$ & Sex & $\begin{array}{c}\text { Spleen Weight, } \\
\text { Grams }\end{array}$ & $\begin{array}{l}\text { Body Weight, } \\
\text { Grams }\end{array}$ & Sex & $\begin{array}{c}\text { Spleen Weight, } \\
\text { Grams }\end{array}$ \\
\hline 465 & 9 & 3.50 & 576 & q & 1.20 \\
\hline 634 & $\delta$ & 1.75 & 376 & ts & 0.60 \\
\hline 580 & p & $5 \cdot 5^{\circ}$ & 502 & 8 & 0.65 \\
\hline 579 & t & 2.50 & 203 & 3 & 0.75 \\
\hline 485 & $q$ & $x .03$ & 308 & q & 0.64 \\
\hline 289 & q & 0.75 & 444 & t & 0.35 \\
\hline 502 & q & I. $5^{\circ}$ & 308 & $q$ & 0.40 \\
\hline 672 & $q$ & 6.00 & 348 & t & 0.40 \\
\hline 680 & $\delta$ & I. 75 & 550 & 우 & 0.90 \\
\hline 602 & 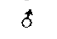 & 3.10 & & & \\
\hline Average 548.8 & & 2.74 & 401.7 & & 0.65 \\
\hline
\end{tabular}

From this table we note that the average spleen weight of the pigs showing a reaction was over four times the average weight of the spleens from non-reacting pigs. On the other hand, the average body weights of the reacting animals was only about one-third greater than that of the non-reacting pigs. This difference in body weights is accounted for by the fact that it was mainly young pigs which did not show a reaction.

With one exception the spleen weight of every guinea-pig showing a reaction was greater than one gram, while of the non- 
reacting animals only one shows a spleen wejght of one gram or over.

It is further noted from this table that the sexes are distributed about equally in the two groups. This shows that the males are as likely to be infected as the females. This point has not always been clearly recognized in studying the disease in cattle.

The results shown in this table are in agreement with the results obtained by Smith and Fabyan on experimentally inoculated guinea-pigs. These results confirm the conclusions drawn from the serum reactions.

In order to furnish definite proof that these lesions and blood reactions are due to infection by the abortion bacillus it is necessary to isolate the organism from guinea-pigs showing these reactions. This has been done in two instances. In one case cultures were obtained from the spleen and liver and in the other from the spleen alone. Cultures made from several other reacting pigs did not show any growth of this organism. I have noted at another place ${ }^{x}$ that the abortion organism when first isolated is frequently very difficult to grow under laboratory conditions. This may account for the failure to obtain a culture in every case.

In February, I9 2, a number of apparently healthy guinea-pigs two or three weeks old were removed from the general herd and placed in a separate building at some distance from the piggery. During May and June a number of these young pigs were killed for complement. None of these showed any evidence of infection. This would indicate that the strict isolation has prevented the further spread of the infection.

It is believed that these data are of interest in showing that, under certain conditions at least, the bacillus of bovine infectious abortion can become epizootic among animals other than cattle. It opens the possibility that under similar conditions other domestic. animals might become infected. 